\title{
Botulismoa, kasu bat oinarri hartuta
} Botulism, a case report

Larraitz Etxeberria Arizmendi ${ }^{1}$, Amaia Palomar Palacios ${ }^{1}$, Nerea Beristain Mendizabal ${ }^{1}$, Laura Mungia Nieva ${ }^{1}$, Lorea Alvarez Guerrico ${ }^{2}$, Miguel Urtasun Ocariz ${ }^{3}$, Jose Ramon Aginaga Badiola $^{1}$

${ }^{1}$ Donostia Unibertsitate Ospitaleko Larrialdi Zerbitzua

${ }^{2}$ Gipuzkoako Osasun Publikoko Zuzendariordetza, Epidemiologia Unitatea

${ }^{3}$ Donostia Unibertsitate Ospitaleko Neurologia Zerbitzua

larraitz.echeverriaarizmendi@osakidetza.eus

\section{Laburpena}

Botulismoa Clostridium botulinum bakterioak sortzen duen neurotoxinak eragindako gaixotasuna da. Lotura neuromuskularretan eragiten duenez, oso larria izatera irits daitekeen sindrome klinikoa eragin dezake, arnas muskuluen paralisia eragiteraino. Kutsatzeko erarik ohikoena, elikagai bidezkoa $\mathrm{da}$, agerraldi epidemiologiko gehienak elikagaiak prestatzeko metodo desegokiekin erlazionatuta egonda. Horregatik, nahitaezkoa da kasu susmagarri guztiak garaiz identifikatzea horien aurrean neurriak sasoiz hartu ahal izateko.

Donostia Unibertsitate Ospitaleko Larrialdi Zerbitzura botulismoaren susmo klinikoa zuen 23 urteko emakumea bertaratu zen, etxean egindako hegaluze-kontserba kontsumitu ondoren; azkenik Neurologiako zerbitzuan ingresatuta geratu zen. Diagnostikoa egiteko beharrezkoa da lagin kliniko batean edo elikagai susmagarriaren lagin batean toxina botulinikoa detektatzea. Era berean, kutsatuta dagoen elikagaiaren identifikazioa egitea garrantzitsua da, horrela pertsona gehiagoren kutsatzeak saihestu ahal izateko. Hori dela eta, botulismoa, osasun publikoko emergentzia eta berehala jakinarazi behar den aitortu beharreko gaixotasuna da.

Gako-hitzak: botulismoa, elikagai-intoxikazioa, antitoxina botulinikoa.

\section{Abstract}

Botulism is a disease resulting from the action of a neurotoxin released by the bacterium Clostridium botulinum. Due to its effect at the neuromuscular junction, it can lead to a severe clinical syndrome that may progress to weakening of the breathing muscle and respiratory arrest. The most common way of infection is the result of the consumption of contaminated food, typically related to improper methods of food preparation. Therefore, it is very important to detect all the suspected cases at an early stage so that necessary measures can be taken.

A 23 years old woman with clinical suspicion of botulism was presented in the Emergency room of Donostia University Hospital after eating a home prepared tuna can, being finally admitted to Neurology ward. For botulism diagnosis, a serum/stool sample or a sample of the suspected food-can is needed to detect and confirm the presence of botulinic toxin. Additionally, it is crucial to identify the poisoned products to avoid more infected cases. Thus, botulism is a notifiable disease and should always be reported to a public health institution.

Keywords: Botulism, foodborne diseases, botulinum antitoxin 
Bidalia: 354 - 21.01.27

Onartua: 2021.05.07

http://doi.org/10.26876/osagaiz.1.2021.354

\section{Sarrera}

Clostridium botulinum bakterioak sortzen duen neurotoxinak botulismoa eragiten du,oso larria eta hilgarria izan daitekeen gaixotasun arraroa. Clostridium botulinum endospora erara bizi den bazilo anaerobioa da. Bazilo hori mundu osoan aurki dezakegu, bere erreserborio naturalak lurzorua, uretako sedimentuak eta animalia batzuen hesteak izanik. Gure herrialdean B genotipoa da gaixotasunaren eragile nagusia. Horrez gain, Clostridium baratiik sortutako $F$ neurotoxina eta Clostridum butyricum bakterioek sortutako E neurotoxina ere izan daitezke gaixotasunaren sortzaile noiz edo noiz.

Clostridium botulinum bakterioak sortzen duen neurotoxinak azetilkolinaren askapena blokeatzen du lotura neuromuskularrean nerbio-kinadaren transmisioa ekidinez. Ondorioz, beheranzkoa eta simetrikoa den paralisia (paralisi flazidoa) eragiten du. Horrek, kasu larrienetan, arnas muskuluen paralisia eragin dezake, eta, hori dela eta, elikagai kutsatuen banaketa saihestea osasun publikoko emergentzia da, botulismoa aitortu beharreko gaixotasuna izanik (1).

Neurotoxina horiek irenstea izaten da botulismo izenez ezagutzen dugun sindrome klinikoaren jatorri ohikoena, elikagaien bidezko transmisioa, alegia. Hala ere, hainbat transmisio modu ezagutzen dira:

- Gure inguruneko agerraldi epidemiologiko gehienak elikagaiak prestatzeko metodo okerrekin daude erlazionatuta. Elikagaien kontserbak prestatzeko orduan beharrezko tenperatura eta denbora ez erabiltzeak Clostridium endospora inaktibatzea ekidingo du eta horrek neurotoxina sortzea ahalbidetu. Endospora inaktibatzeko, elikagaia 10 minutuz 121 gradutan irakitea beharrezkoa da. Hori dela eta, toxina azidotasun gutxiko (4,5eko pH-a baino gehiagoko) elikagaietan eta hermetikoki etxean ontziratu eta hozkailutik kanpo mantendutakoetan ager daiteke gehienbat.

- Hesteen kolonizazioaren ondoriozko botulismoa, irentsi eta gero hesteetan ugaltzen diren bakterioen toxinek eragiten dute. Horiek adibidez eztian eta hautsean aurki ditzakegu. Maizago agertzen da urtebete baino gutxiagoko haurretan. Helduetan, immunogutxituetan, hesteetako nahasmendu anatomiko edo funtzionala dutenen kasuan eta antibiotikoak hartzen ari direnetan azaldu izan da, hesteetako mikrobiotaren aldaketak toxinak ugaltzea errazten baitu.

- Zaurien ondoriozko botulismoan endosporak zaurian sartu, ernaldu eta bertan ugaltzen dira. Traumatismo baten ondorioz zauria edo haustura kutsatu eta gero edo droga parenteraleko erabiltzaileen kasuan, zulatzeak eragindako zauria kutsatu eta gero $(2,3)$.

- Botulismo iatrogenikoa: arrazoi terapeutiko edo estetikoengatik A edo B toxina ziztatzean gertatzen da $(3,4)$.

- Botulismoa eragile biologiko terrorista gisa: toxina aerosol moduan zabalduta edo ur eta elikagaien kutsaduraren bidez (3).

- Ez da pertsonen arteko transmisioaren ondoriozko kasuen berri eman.

Botulismoa gutxitan azaltzen den infekzioa da. Urtero batez beste 110 kasuren berri ematen da Estatu Batuetan. Horietatik \% 20-25 elikagai bidezko kutsatzearekin erlazionatuta dago, \% 70-75 
haurren hesteen kolonizaziorekin eta \% 5-10 zaurien bidezkoekin (1). Europar Batasunak 100.000 biztanleko 0,02ko tasa dauka. Espainian, konkretuki, 12 kasuren berri izan zen 2018an eta horietatik 11 elikagaiekin erlazionatuta egon ziren eta soilik bat hesteen kolonizazioaren ondoriozko botulismoarekin (5).

Botulismoaren diagnostikoa egiteko klinika bateragarri bat, laborategiko irizpide batzuk eta irizpide epidemiologiko batzuk bete behar dira.

Transmisio moduaren araberako klinika:

- Elikagaien bidez transmititutako forma klasikoa edo botulismoa: sintomak toxina botulinikoa irentsi ondorengo 12-36 orduetan agertu ohi dira, sintomen agerpena 2 astera luza daitekeela kontuan izanik. Fase prodromiko batekin hasi ohi da, goragale eta gonbitoak, sabeleko mina, beherakoa eta aho lehorra izan ohi dira lehen sintomak eta ondoren gaixotasunaren ohiko klinika agertzen da, hala nola aldebiko garezurreko neuropatia (ikusmen lausoa, diplopia, nistagmoa, ptosia, disfagia, disartria eta aurpegiaren ahultasuna) eta beheranzko ahultasun simetrikoa goiko gorputz-adarretatik hasita beheko gorputzadarretaraino.

- Hesteen kolonizazioaren ondoriozko botulismoa (digestio-sistemaren heste-kolonizazioa, bularreko haurretan ohikoagoa): bularreko haurraren edo helduaren heste-botulismoan anatomia eta hesteetako mikrobiota erasaten direnez, 6 sintoma hauetako bat izaten dute: idorreria, letargia, jateko gogorik eza, betazalen ptosia, disfagia eta ahultasun muskular orokorra (adin pediatrikoaren kasuan ohikoagoa da disfagia, disartria eta ahultasun orokorra agertzea).

Lehen sintomak idorreria eta ahulezia izango lirateke, zurrupaketa-ahuleziarekin eta jateko zailtasunarekin jarraituz. Beheranzko hipotonia edo hipotonia global baterantz joko lukete, sialorrea biziarekin, suminkortasunarekin eta negar ahularekin. Koadro klinikoa aldakorra izan daiteke, gaixotasun arin batetik haurra bat-batean hiltzeraino.

- Zaurien ondoriozko botulismoa: gaixotasunaren ohiko sintomak aurkituko genituzke zuzenean, aldez aurretik fase prodromiko bat ikusi gabe. Normalean 10 egun inguruko inkubazio-aldia izango luke. Forma kliniko honetan zauriaren infekzio bakterianoaren ondorioz sukarra eta leukozitosia aurki genitzake.

Klinika bateragarri edo susmagarri baten aurrean egin beharreko laborategiko probak eta bete beharreko irizpideak honako hauek dira:

- Clostridium-en isolamendua hazkuntza anaerobioan. Hesteetako botulismoaren kasuan gorozkietan (ez elikagaiek transmititutakoan) eta zaurien ondoriozkoan zaurian bertan.

- Lagin kliniko batean toxina botulinikoa detektatzea. Elikagaien bidez transmititutako kasuetan, serumean toxina botulinikoa agertzen da jan eta 12 egunera arte, baita gorozki, gonbito edo elikagaietan ere.

Irizpide kliniko eta analitiko horiez gain, gutxienez bi harreman epidemiologiko hauetako bat beharko litzateke diagnostikoa egin ahal izateko: iturri komun batekiko edo elikagai edo edateko ur kutsatuekiko esposizioa (6).

Aurretik zehaztutako informazioaren arabera, honela sailkatuko genituzke kasuak:

- Kasu susmagarria: irizpide klinikoak betetzen dituen eta botulismoaren diagnostiko mikrobiologikoaren proba bat eskatu zaion pertsona. 
- Kasu probablea: irizpide klinikoak betetzen dituen eta harreman epidemiologikoa duen pertsona.

- Baieztatutako kasua: irizpide klinikoak eta laborategiko irizpideak betetzen dituen pertsona (6).

Infekzio-iturri berarekiko esposizioan egondako edozein botulismo motaren bi kasu edo gehiago atzemanez gero, agerraldi baten aurrean egongo ginateke (6).

Botulismoa lotura neuromuskularreko inplikazioa duten patologien konglomeratuaren barruan kokatzen da. Botulismo-kasu susmagarri bat aurkitzen dugun bakoitzean, diagnostiko bereizle bat egin behar dugu antzeko sintoma klinikoak dituzten patologiekin: guillain-barré sindromea, miastenia gravis, iktusa, nerbio-sistemarako kaltegarriak diren substantzien intoxikazioa, lambert-eaton sindromea, nerbio-sistema zentraleko (NSZ) infekzioak, NSZko tumorea, hanturazko miopatiak, diabetesaren konplikazioak eta hipotiroidismoa, horien artean.

Kutsatutako elikagaien eraginpean edo botulismo-intoxikazio susmopean dauden paziente guztiak zorrotz kontrolatu behar dira. Botulismoaren ondoriozko heriotza-kausa nagusia arnas gutxiegitasuna denez, pazientearen monitorizazio estua ezinbestekoa da, kasu larrietan intubazio eta bentilazio mekanikoa beharrezkoak izanik.

Toxina honen intoxikazioaren aurkako tratamendu espezifikoa antitoxina botulinikoa da (7). Diagnostiko klinikoa egin eta ahal den lasterren eman behar da eta, susmoa altua bada, ez zaie proba osagarrien emaitzei itxarongo, egoera hobetzeko aukera gutxiago izango baititugu, administrazioa atzeratzen bada. Zaldien serumetik eratorritako produktua da eta \% 20k anafilaxia edo III. motako hipersentikortasuna sor dezakeenez, administrazioaren aurretik sentsibilizazio-probak egitea gomendatzen da.

Antitoxina horrek odol-korrontean dauden toxinak neutralizatzen ditu, hau da, toxina bere itura lotzea ekiditen du. Hala ere, egoera neurologikoa ez da berehala lehengoratuko, behin betiko errekuperazioa nerbio-bukaerak birsortzearen menpe dagoelako, eta asteak eta hilabeteak iraun dezake. Dena den, antitoxinak gaixotasunaren progresioa moteldu edo eten dezake. Urtebetetik beherako pazienteen kasuan giza immunoglobulina erabiltzen da (8).

Elikagaien bidezko intoxikazioen tratamenduan ikatz aktibatua ere eraginkorra izan daiteke. Baita laxante edo enemen erabilera ere digestio-aparatuaren garbiketa eragin nahian, betiere ileo paralitikoa edo buxadura baztertu ondoren. Antibiotikoen erabilera ez dago onartua, toxinen askatzea azkartu baitezakete. Antibiotikoak zaurien bidezko botulismo-kasuetan erabiltzen dira, antitoxina eta zauriaren garbiketa zabalarekin batera $(9,10)$.

\section{Kasuaren aurkezpena}

2019ko irailaren 16an, botulismoaren susmo klinikoa zuen 23 urteko emakumea Donostia Unibertsitate Ospitaleko Larrialdi Zerbitzura joan zen, irailaren 4an eta 6an etxean ontziratutako hegaluze-kontserbak kontsumitu eta gero, irailaren 7an ikusmen lausoa eta aho lehorra izan zituen. Egun batzuk geroago, disfagia, aurpegiko ahultasuna, aldebiko betazalen ptosia eta idorreria gehitu ziren.

Pazientearen gurasoek ere kontserba berak kontsumitu zituzten, kantitate txikiagoan, eta aurkeztu zuten sintomatologia arinagoa izan zen; aho lehorraren sentsazioa besterik ez zuten aurkeztu.

Inkesta epidemiologikoaren ondoren, beste 14 lagun eta senidek hegaluze-kontserba horiek kontsumitu eta antzeko sintomak zituztela ikusi zen. Egoera Elikagaien Osasun Unitateari jakinarazi zitzaion. 
Pazientea Ospitaleko Larrialdi Zerbitzuan aztertu ondoren, Oftalmologiako zerbitzura bidali zuten azterketa sakonago bat egiteko. Azterketa egin ondoren,Neurologiako zerbitzuan ingresatu zuten botulismo-susmopean. Haren aita eta ama ere, sintoma arinagoak zituztela, Neurologiako zerbitzuan ingresatu zituzten behaketarako.

Guztira 14 izan ziren elikagai susmagarria kontsumitu zutenak, 5 familia-taldetan banatuta. Hegaluzekontserbak etxe partikular batean egin eta senitartekoei eta gertuko ezagunei banatu zitzaizkien.

Familia-taldeen informazio epidemiologikoa jarraian zehazten da (Ikus 1. taula).

1. taula.

\begin{tabular}{|c|c|c|c|c|c|c|c|}
\hline & Pazientea & Kontsumo-data & $\begin{array}{l}\text { Sintomen } \\
\text { agerpena }\end{array}$ & Ingresua & $\begin{array}{c}\text { Tratamen- } \\
\text { dua }\end{array}$ & Laginak & Emaitzak \\
\hline \multirow{3}{*}{ 1. Familia } & + $23 \mathrm{u}$. & $\begin{array}{c}\text { 09/04 eta } \\
09 / 08\end{array}$ & 09/07 & BAI & BAI & $\begin{array}{c}\text { Gorozkietan eta } \\
\text { serumean }\end{array}$ & NEGATIBOA \\
\hline & ô $56 \mathrm{u}$. & 09/08 & 09/09 & BAI & BAI & $\begin{array}{c}\text { Gorozkietan eta } \\
\text { serumean }\end{array}$ & NEGATIBOA \\
\hline & 우 $53 \mathrm{u}$. & 09/08 & 09/09 & BAI & EZ & $\begin{array}{l}\text { Gorozkietan eta } \\
\text { serumean }\end{array}$ & NEGATIBOA \\
\hline \multirow{3}{*}{ 2. Familia } & $q 54 \mathrm{u}$. & $\begin{array}{c}\text { 09/11 eta } \\
09 / 14\end{array}$ & $09 / 14$ & BAI & BAI & $\begin{array}{c}\text { Gorozkietan eta } \\
\text { serumean }\end{array}$ & NEGATIBOA \\
\hline & ô $53 \mathrm{u}$. & 09/11 & EZ & EZ & EZ & EZ & \\
\hline & o $19 \mathrm{u}$. & $09 / 11$ & EZ & EZ & EZ & EZ & \\
\hline \multirow{4}{*}{ 3. Familia } & ô $56 \mathrm{u}$. & $\begin{array}{c}08 / 30 \text { eta } \\
09 / 07 \\
\text { bitartean }\end{array}$ & 09/02 & BAI & EZ & $\begin{array}{c}\text { Gorozkietan eta } \\
\text { serumean }\end{array}$ & NEGATIBOA \\
\hline & o $16 \mathrm{u}$. & $\begin{array}{c}08 / 30 \text { eta } \\
09 / 07 \\
\text { bitartean }\end{array}$ & 09/02 & BAI & EZ & $\begin{array}{c}\text { Gorozkietan eta } \\
\text { serumean }\end{array}$ & NEGATIBOA \\
\hline & 우 $55 \mathrm{u}$. & $08 / 30$ & 09/02 & EZ & EZ & Serumean & NEGATIBOA \\
\hline & ô 19 u. & $08 / 30$ & 09/02 & EZ & EZ & Serumean & NEGATIBOA \\
\hline \multirow[t]{2}{*}{ 4. Familia } & + $47 \mathrm{u}$. & $\begin{array}{c}\text { Hainbat aldiz } \\
09 / 09 \text { eta } \\
09 / 16 \\
\text { bitartean }\end{array}$ & 09/18 & BAI & EZ & $\begin{array}{c}\text { Gorozkietan eta } \\
\text { serumean }\end{array}$ & NEGATIBOA \\
\hline & ò 49 u. & 09/15 & EZ & EZ & EZ & EZ & \\
\hline \multirow{2}{*}{ 5. Familia } & $975 \mathrm{u}$. & $\begin{array}{l}\text { Ez dira datak } \\
\text { zehazten }\end{array}$ & EZ & EZ & EZ & EZ & \\
\hline & ठิ $87 \mathrm{u}$. & $\begin{array}{l}\text { Ez dira datak } \\
\text { zehazten }\end{array}$ & EZ & EZ & EZ & EZ & \\
\hline
\end{tabular}

Hamalau pertsona horietatik $9 \mathrm{k}$ sintomak aurkeztu izan zituzten (\% 64ko eraso-tasa). Kaltetutako pertsonak 6 emakume eta 3 gizon izan ziren, 16 eta 56 urte bitartekoak.

Aurkeztutako sintomak arinak izan ziren: aho lehorra, disfagia, diplopia, idorreria eta ikusmen lausoa.

Guztira 7 gorotz-lagin eta 9 serum-lagin jaso ziren Clostridium botulinum bakterioaren intoxikazioa egiaztatzen duen ikerketa mikrobiologikoa egiteko. Lagin horiek Mikrobiologiako Zentro Nazionalera bidali ziren, eta guztien emaitzak negatiboak izan ziren.

Elikagaien Osasun Unitateak elikagai susmagarrien lagin desberdinak jaso zituen eta Elikadura Zentro Nazionalera bidali. Aztertutako hiru ontzietatik bitan toxina botulinikoaren presentzia aurkitu zen. 
Larraitz Etxeberria Arizmendi , Amaia Palomar Palacios, Nerea Beristain Mendizabal, Laura Mungia Nieva, Lorea Alvarez Guerrico, Miguel Urtasun Ocariz, Jose Ramon Aginaga Badiola

Aurkezturiko klinika arina izanik, sintomak izandako 9 pertsona horietatik 7 ospitaleratuak izan ziren, eta horietatik hiruk bakarrik jaso zuten antitoxina heptabalentea.

Agerraldia susmatu zen unetik oraindik kontsumitu gabeko kontserba guztiak suntsitzeko deia egin zen.

\section{Botulismo-kasu baten aurrean hartu beharreko neurriak}

Sintomak hasi baino astebete lehenago kontsumitutako elikagai susmagarri guztien laginak, batez ere azidotasun gutxiko etxeko kontserbak (barazkiak, arrain ketuak, olioan prestatutako jakiak...) eta hutsean ontziratutako elikagaien laginak hartu behar dira, elikagai kausalaren identifikazioa lehentasunezkoa izanik.

Kasuaren kontaktuen kudeaketa ez da beharrezkoa, ez baitago kontaktu zuzen bidezko transmisiorik. Hala ere, elikagai susmagarria kontsumitu duten pertsonen bilaketa aktiboa egin behar da, medikubehaketa eta dagokion inkesta egingo zaie.

Botulismo-kasu indibidualen aurrean, Autonomia Erkidegoak kasu susmagarri, posible eta konfirmatuak Epidemiologiako Zentro Nazionalari (EZN) jakinaraziko dizkio zaintza epidemiologikoaren sare nazionalaren bitartez. Astero inkesta epidemiologikoaren informazioa bidaliko dio.

Agerraldien kasuan, Autonomia Erkidegoko zaintza-zerbitzuak agerraldiaren behin betiko txostena eta inplikatutako kasuen inkesta epidemiologikoak bidaliko dizkio EZNri ikerketa bukatu eta gehienez hiru hilabeteko epean.

Komertzializatutako elikagai edo nahitako kutsadura baten aurrean, Autonomia Erkidegoak Osasun Ministerioko alerta eta larrialdien zentro koordinatzailea eta EZN jakinaren gainean jarriko ditu eta hartu beharreko neurriak erabakiko dituzte. Beharrezkoa bada, Osasunaren Mundu Erakundea eta Europar Batasuneko alerta-sistema ere jakinaren gainean jarriko dituzte.

\section{Ondorioak}

Botulismoa, Clostridium botulinum bakterioak sortutako neurotoxinak lotura neuromuskularrean garatzen duen jarduerak eraginda agertzen da. Lehenengo sintoma neurologikoak elikagaia kontsumitu eta 12-36 ordutara agertu ohi dira eta horien artean nabarmentzekoak dira ikusmen lausoa, diplopia, nistagmoa, ptosia, disfagia, disartria eta beheranzko ahultasun simetrikoa. Beraz, kasu susmagarri baten aurrean lotura neuromuskularrari eragiten dioten patologiekin diagnostiko bereizlea egin behar da lehenbailehen.

Prebentzio moduan, gure inguruneko agerraldi epidemiologiko gehienak endosporak hiltzen ez dituzten elikagaiak prestatzeko metodoekin erlazionaturik daudenez (prestakuntzan behar den beste tenperatura altua eta denbora ez erabiltzeak eraginda, alegia), etxeko kontserbak kontsumitu aurretik behar bezala kozinatzea edo berotzea ezinbestekoa da, baita kutsaduraren ebidentzia duten edo puztutako edo irekitako ontziak baztertzea ere. Segurtasun-neurri guztiak har daitezen, gaixotasun honen aurrean biztanleria kontzientziatzea beharrezkoa da.

Botulismoaren diagnostikoa egiteko iturri komun batekiko edo elikagai susmagarria kontsumitu duten bilaketa aktiboa ezinbestekoa da, eta lagin klinikoan edo aztertzen ari garen elikagaian toxinaren detekzioa egin behar da. 
Arraroa, prebalentzia baxua izaten jarraitzen duen arren, oso hilgarria izan daitekeenez eta intoxikazio honen aurkako tratamendu espezifikoa, euskarri-neurriez gain, antitoxina botulinikoa denez, garbi susmatzen denean lehenbailehen ospitaleratu eta antitoxina eman behar da.

\section{Erreferentzia bibliografikoak}

1. Weimer T, Shefner JM, Goddeau RP. Overview of neuromuscular junction toxins. [Eguneratuta: 2019-07-12; Kontsulta: 2020-12-20]. Hemen: Uptodate [Internet] Waltham (MA): Uptodate.c2020. [28 or.]. Eskuragarri: https://www.uptodate.com/contents/overview-ofneuromuscular-junction-

toxins/print?search=botulismo\&source=search result\&selectedTitle=3 83\&usage type=default \&display rank $=3$

2. AMSE: Asociación de Médicos de Sanidad Exterior [Internet]. Huelva: Asociación de Médicos de Sanidad exterior; c2020. Botulismo. Información epidemiológica: botulismo, epidemiología y situación mundial; 2012ko ekainak 6 [Kontsulta: 2020-12-20]. [2 or.]. Eskuragarri: https://www.amse.es/informacion-epidemiologica/168-botulismo-epidemiologia-y-situacion

3. P Samuel Pegram, MD, FACPSean M Stone, MD, FACEP. Botulism. [Eguneratuta: 2020-12-07; Kontsulta: 2020-12-20]. Hemen: Uptodate [Internet] Waltham (MA): Uptodate.c2020. [32 or.]. Eskuragarri:

https://www.uptodate.com/contents/botulism?search=botulismo\&source=search result\&select edTitle=1 83\&usage type=default\&display rank=1

4. Quevedo-Florez LA, Nariño-Gonzalez D, Aguiar-Martinez LG, et al. Botulismo iatrogénico en paciente con distonía cervical: Reporte de caso. Rev Mex Neuroci. 2016;17(2):99-103. Eskuragarri: https://www.medigraphic.com/cgi-bin/new/resumen.cgi?IDARTICULO=66467

5. Resultados de la vigilancia epidemiológica de las enfermedades transmisibles. Informe anual. Años 2017-2018. [Internet]. Instituto de Salud Carlos III [Kontsulta: 2020-12-20]. Eskuragarri: PROTOCOLOS DE LA RED NACIONAL DE VIGILANCIA EPIDEMIOLÓGICA (isciii.es)

6. Botulismoa: Zaintza epidemiologikoaren sare nazionaleko (ZESN) protokoloen egokitzapena [Internet]. Vitoria-Gasteiz: Eusko Jaurlaritza, Osasun Saila; 2020 [Kontsulta: 2020-12-01]. 18 or. Eskuragarri:

https://www.euskadi.eus/contenidos/informacion/vigilancia protocolos/eu def/adjuntos/Botuli smoa eus.pdf

7. Botulism Equine Heptavalent Antitoxin (ABCDEFG). [Eguneratuta: 2020-07-17; Kontsulta:202012-20]. Hemen: Dynamed [Internet]. Ipswich (MA): EBSCO Information Services. c2020- . Eskuragarri: $\quad$ https://www.dynamed.com/drug-monograph/botulism-equine-heptavalentantitoxin-abcdefg

8. Arnon SS, Schechter R, Maslanka SE, Jewell NP, Hatheway CL. Human Botulism Immune Globulin for the Treatment of Infant Botulism. N Engl J Med. 2006;354: 462-71. Eskuragarri: http://dx.doi.org/10.1056/ NEJMoa051926

9. Chalk $\mathrm{CH}$, Benstead TJ, Pound JD, Keezer MR. Medical treatment for botulism [Internet]. Cochrane Database Syst Rev. 2019 Api 17 [Kontsulta: 2020-12-20]; 4(4): CD008123. Eskuragarri: https://doi.org/10.1002/14651858.CD008123.pub4 
Larraitz Etxeberria Arizmendi , Amaia Palomar Palacios, Nerea Beristain Mendizabal, Laura Mungia Nieva, Lorea Alvarez Guerrico, Miguel Urtasun Ocariz, Jose Ramon Aginaga Badiola

10. Tejada García M, Guindel Jiménez C. Tratamiento con antitoxina botulínica en dos casos de botulismo alimentario. Farm Hosp. 2010;34(1):47-48. Eskuragarri: https://www.elsevier.es/esrevista-farmacia-hospitalaria-121-pdf-S1130634309000087 